[RAdiocarbon, Vol 22, No. 3, 1980, P 947-949]

\title{
REPORT ON THE WORKSHOP ON THE CALIBRATION OF THE RADIOCARBON DATING TIME SCALE
}

\author{
P E DAMON*, J C LERMAN*, AUSTIN LONG*, \\ BRYANT BANNISTER*, JEFFREY KLEIN**, \\ TIMOTHY LINICK***, \\ and \\ other Participants of the Workshop
}

\begin{abstract}
Last winter, Tucson was warmed by some lively and very useful group discussions concerning calibration of the radiocarbon time scale. Thanks to support from the USA National Science Foundation, it was possible to bring together representatives of the major USA laboratories working on the calibration problem as well as statisticians and some observers representing users and the funder. The workshop was convened by $\mathrm{P} \mathbf{E}$ Damon, J C Lerman, Bryant Bannister, and Austin Long, and met at the University of Arizona in Tucson during the week of January 29, 1979 to February 2, 1979 supported by the NSF Grant EAR 78-23584. Dendrochronologic work at the Laboratory of Tree-Ring Research of the University of Arizona was represented by Bryant Bannister, C W Ferguson, D A Graybill, and V G LaMarche, Jr. For the radiocarbon work, the laboratories and their representatives were: La Jolla (H E Suess, Timothy Linick), Pennsylvania (Henry Michael, Jeffrey Klein), Arizona (P E Damon, J G Lerman, Austin Long), and Washington (Minze Stuiver, Robert Burk). Minze Stuiver also represented the journal, RADIOCARBON. The observers from the USA geologic and archaeologic societies were J S Dean, R E Taylor, and E M Davis. J E Yellen represented the NSF. D J Donahue represented the recently created Radiocarbon Accelerator Regional Facility at the University of Arizona. Statisticians who attended the meeting were $\mathrm{J}$ W Tukey (Princeton University and Bell Labs) C M Clark (Monash University, Australia), and Albrecht Neftel (Bern, visiting at La Jolla).

The primary objective of the Workshop was to produce a single carbon-14 calibration table using a data set composed only of isotope analyses of dendrochonologically dated wood produced by laboratories funded by the USA National Science Foundation.

The small workshop group, in total, 21 persons, examined the data sets from the individual laboratories, merged them into a composite set, and studied the implications that the retrieved 'wiggles' would have for geophysicists.

Data analysts evaluated the accuracy and precision of this composite radiocarbon data set in conjunction with radiocarbon experts and dendrochronologists. From this consortium emerged the method for producing a radiocarbon calibration (see Klein and others, 1980).

* Conveners of the Workshop, University of Arizona, Tucson, Arizona 85721

** Department of Physics and Radiocarbon Laboratory, University of Pennsylvania, Philadelphia, Pennsylvania 19104

*** Mt Soledad Radiocarbon Laboratory, University of California, San Diego, California 92307
\end{abstract}


A second objective was to evaluate and decide on the statistical validity of the ${ }^{14} \mathrm{C}$ variations known as the 'de Vries effect.' These fluctuations are particularly important for solar scientists and geophysicists as a source of information about the magnitude of variation of geophysical and solar factors in the past. Until now, considerable uncertainty has existed about the statistical validity of many of these fluctuations. The group considered, as well, the limitations that must be imposed on the calibration curve which will soon be offered for users of radiocarbon dating.

The most important accomplishment of the Workshop was the participants' universal agreement to accept a single calibration curve based on the composite data set. With the advice and direction of J W Tukey, this curve will enable construction of a set of calibration tables. A 'geophysical curve' has already been constructed from a procedure also adopted by consensus at the Workshop (see Klein and others, 1980). This 'curve' represents the best estimate of the 'wiggles' in carbon-14 concentration presently available from the bristlecone pine and sequoia records. To this end, we had to explore different methods and orders of curve fitting, and test for the robustness (persistence and reproducibility) of the wiggles retrieved by the different techniques.

Members of the Workshop unanimously agreed to constitute themselves as an 'Interim Committee for the Calibration of the Radiocarbon Dating Time Scale' until this 10th International Radiocarbon Conference, where the committee presented the results of the Workshop and post-workshop activities (see Klein and others, 1980). The present function of this committee is the accomplishment of workshop goals that were formulated and approved by the participants (see Appendix).

Pursuant to these goals, Workshop members reviewed the numerical methods to be used and the problems of representing data by a smooth curve. Preference was given to robust methods (see Tukey, 1977; 1979; Mosteller and Tukey, 1977; and bibliography mentioned therein). Programs for curve-fitting written by C M Clark and Jeffrey Klein were installed and tested in the Cyber-175 computer at the University of Arizona Computing Center before the Workshop, and partially debugged during the meeting. Curve generation continued after the workshop. Following endorsement of Klein's approach by the workshop, Professor Tukey presented, and the workshop accepted, a strategy for attaining Goal III ( $i e$, the geophysical wiggly $\Delta$-curve) as described by Klein and others (1980). In addition, the Workshop decided to recommend the establishment of an International Committee to extend the Workshop to include all available data throughout the world. 


\section{APPENDIX}

\section{Goals}

Goal I. Construct a calibration table for users with single dates not connected in a tight time series. This table will yield a range of possible calendar years at 95 percent confidence interval corresponding to a given carbon-14 date with particular laboratory precision. Consequently, one will enter the table not only with a ${ }^{14} \mathrm{C}$ date but also with an uncertainty.

Goal II. Construct a series of graphs of $\mathrm{T}\left({ }^{14} \mathrm{C}\right)$ vs $\mathrm{T}(\mathrm{D})$ with data points and with as many of the high frequency components as seem to be warranted by the data. These graphs would represent different time intervals for the composite data set and the individual laboratory sets. These graphs are intended for use in specialized problems where maximum information is required. Use of graphs is at user's risk with respect to accuracy of interpretation.

Goal III. Construct a set of graphs of $\Delta$ vs $\mathrm{T}(\mathrm{D})$ with data points and with as many of the high frequency components as seem to be warranted by the data. These graphs would represent different time intervals for the composite data set and the individual laboratory sets. These graphs are intended for use in geophysical, geochemical, and solar physics applications. Use of these graphs is at user's risk with respect to accuracy of interpretation.

Goal IV. Publish the revised data set in the same format for Arizona, La Jolla, Pennsylvania, and Yale laboratories recalculated to 0.950 times the activity of the NBS oxalic acid standard sample. Other laboratories may want to revise their published data sets in the same format for simultaneous publication. Publication of these revised data sets is intended to remove current confusion in use of published data by users who are not familiar with the calibration problems.

Goal $V$. Publish the results of Goals I to IV in a single issue of RADIOCARBON with detailed instructions for producing modified graphs and tables and for the use of the graphs and tables.

Goal VI. With publication of the techniques for updating the graphs and table, a final goal is to provide a vehicle for continuous updating of the calibration table and graphs. This goal will be achieved by maintaining the computer data sets and by publishing instructions for accessing this information and updating the calibration.

\section{Abbreviations}

$\mathrm{T}\left({ }^{14} \mathrm{C}\right)$ : Radiocarbon date, $i e$, conventional date as calculated using the Libby halflife, 5568 years.

T(D) : Dendrodate, ie, date of dendrochronologic date samples.

$\Delta \quad$ : Relative radiocarbon content as defined in the Notice to Readers (Radiocarbon, 1980 , v 22, no. 1 , p iii).

\section{REFERENCES}

Klein, Jeffrey, Lerman, J C, Damon, P E, and Linick, Timothy, 1979, Radiocarbon concentration in the atmosphere: 8000 -year-record of variations in tree-rings. First results of a USA workshop, in Stuiver, Minze and Kra, Renee, eds, Internatl radiocarbon conf, 10th, Proc: Radiocarbon, v 22, no. 3, p 950-961.

Mosteller, F and Tukey, J W, 1977, Data analysis and regression: a second course in statistics: Reading, Mass, Addison-Wesley, 588 p.

Tukey, J W, 1977, Exploratory data analysis: Reading, Mass, Addison-Wesley, 688 p.

1979, Oral presentation to the workshop on the calibration of the radiocarbon dating time scale, Tucson, Ariz, 29 Jan-2 Feb 1979. 